\title{
Association of gene polymorphisms with myocardial infarction in individuals with or without conventional coronary risk factors
}

\author{
KOHTA NISHIHAMA ${ }^{1}$, YOSHIJI YAMADA ${ }^{1,2}$, HITOSHI MATSUO ${ }^{3}$, TOMONORI SEGAWA ${ }^{3}$, \\ SACHIRO WATANABE ${ }^{3}$, KIMIHIKO KATO $^{4}$, KAZUHIRO YAJIMA $^{4}$, TAKESHI HIBINO ${ }^{4}$, KIYOSHI YOKOI $^{4}$, \\ SAHOKO ICHIHARA ${ }^{1}$, NORIFUMI METOKI ${ }^{5}$, HIDEMI YOSHIDA ${ }^{6}$, KEI SATOH ${ }^{6}$ and YOSHINORI NOZAWA $^{2}$ \\ ${ }^{1}$ Department of Human Functional Genomics, Life Science Research Center, Mie University, 1577 Kurima-machiya, \\ Tsu, Mie; ${ }^{2}$ Gifu International Institute of Biotechnology, Kakamigahara; ${ }^{3}$ Department of Cardiology, Gifu Prefectural \\ Gifu Hospital, Gifu; ${ }^{4}$ Department of Cardiovascular Medicine, Gifu Prefectural Tajimi Hospital, Tajimi; \\ ${ }^{5}$ Department of Internal Medicine, Hirosaki Stroke Center; ${ }^{6}$ Department of Vascular Biology, \\ Institute of Brain Science, Hirosaki University School of Medicine, Hirosaki, Japan
}

Received July 14, 2006; Accepted September 12, 2006

\begin{abstract}
The purpose of the present study was to assess the genetic risk for myocardial infarction (MI) in individuals with or without conventional coronary risk factors and thereby to contribute to the personalized prevention of MI in such individuals. The study population comprised 3483 unrelated Japanese individuals (1913 men, 1570 women). The 1192 subjects with MI (926 men, 266 women) and 2291 controls (987 men, 1304 women) either had or did not have conventional coronary risk factors, including hypertension, hypercholesterolemia, and diabetes mellitus. The genotypes for 164 polymorphisms of 137 candidate genes were determined by a method that combines the polymerase chain reaction and sequence-specific oligonucleotide probes with suspension array technology. Multivariable logistic regression analysis and a stepwise forward selection procedure revealed that nine different polymorphisms were significantly $(\mathrm{P}<0.005)$ associated with MI among individuals with or without hypertension, hypercholesterolemia, or diabetes mellitus: $1018 \mathrm{C} \rightarrow \mathrm{T}$ of GPIBA, $-108 / 3 \mathrm{G} \rightarrow 4 \mathrm{G}$ of $I P F 1,677 \mathrm{C} \rightarrow \mathrm{T}$ of $M T H F R$, and $\mathrm{G} \rightarrow \mathrm{A}$ of $U T S 2$ in hypertensive individuals; $2445 \mathrm{G} \rightarrow \mathrm{A}$ of $F A B P 2,-108 / 3 \mathrm{G} \rightarrow 4 \mathrm{G}$ of $I P F 1,677 \mathrm{C} \rightarrow \mathrm{T}$ of $M T H F R$, $-11,377 \mathrm{C} \rightarrow \mathrm{G}$ of $A C D C, \mathrm{~A} \rightarrow \mathrm{G}$ of $A K A P 10,11,496 \mathrm{G} \rightarrow \mathrm{A}$ of $F 7$, and $46 \mathrm{C} \rightarrow \mathrm{T}$ of $F 12$ in individuals without hypercholesterolemia; $2445 \mathrm{G} \rightarrow \mathrm{A}$ of $F A B P 2$ in diabetic individuals; and $-108 / 3 \mathrm{G} \rightarrow 4 \mathrm{G}$ of IPFI in nondiabetic individuals. Polymorphisms associated with MI may thus differ among individuals with different conventional coronary risk factors. Stratification
\end{abstract}

Correspondence to: Dr Yoshiji Yamada, Department of Human Functional Genomics, Life Science Research Center, Mie University, 1577 Kurima-machiya, Tsu, Mie 514-8507, Japan

E-mail: yamada@gene.mie-u.ac.jp

Key words: genetics, polymorphism, myocardial infarction, coronary heart disease, risk factor of subjects on the basis of such risk factors may thus be important in order to achieve personalized prevention of MI with the use of genetic information.

\section{Introduction}

Myocardial infarction (MI) is an important clinical problem because of its large contribution to mortality. The total number of individuals affected by MI in the United States is 7.2 million, with nearly 170,000 patients dying annually from this condition (1). In Japan, approximately 50,000 people die annually from MI (Ministry of Health, Labor, and Welfare of Japan). The main causal and treatable risk factors for MI include hypertension, hypercholesterolemia, diabetes mellitus, and smoking. In addition to these risk factors, studies have shown the importance of genetic factors and interactions between multiple genes and environmental factors in this condition (2).

Although various association studies (3-8) have attempted to identify genetic variants that contribute to coronary heart disease (CHD) or MI, the genetic components of these conditions have not been determined definitively. In addition, we previously showed that gene polymorphisms that confer susceptibility to MI differ between men and women $(5,9)$. We hypothesized further that the association of polymorphisms with MI might be influenced by the absence or presence of conventional major risk factors for CHD. We have thus examined the relations of polymorphisms to $\mathrm{MI}$ in individuals with or without hypertension, hypercholesterolemia, or diabetes mellitus independently in order to provide a basis for the personalized prevention of this condition.

\section{Materials and methods}

Study population. The study population comprised 3483 unrelated Japanese individuals (1913 men, 1570 women) who either visited outpatient clinics of or were admitted to one of the six participating hospitals (Gifu Prefectural Gifu, Tajimi, and Gero Hot Spring Hospitals; Hirosaki University 
Table I. Characteristics of subjects with or without hypertension.

\begin{tabular}{|c|c|c|c|c|c|c|}
\hline \multirow[b]{2}{*}{ Characteristic } & \multicolumn{3}{|c|}{ Hypertension (+) } & \multicolumn{3}{|c|}{ Hypertension (-) } \\
\hline & Myocardial infarction & Controls & $\mathrm{P}$ & Myocardial infarction & Controls & $\mathrm{P}$ \\
\hline No. of subjects & 870 & 1015 & & 322 & 1276 & \\
\hline Age (years) & $64.4 \pm 10.8$ & $65.5 \pm 10.7$ & 0.0200 & $61.9 \pm 11.6$ & $60.2 \pm 12.1$ & 0.0190 \\
\hline Sex (female/male, \%) & $24.5 / 75.5$ & $51.2 / 48.8$ & $<0.0001$ & $16.5 / 83.5$ & $61.5 / 38.5$ & $<0.0001$ \\
\hline Body mass index $\left(\mathrm{kg} / \mathrm{m}^{2}\right)$ & $23.7 \pm 3.3$ & $23.5 \pm 3.4$ & 0.2450 & $23.5 \pm 3.0$ & $23.2 \pm 2.8$ & 0.1500 \\
\hline Smoker (\%) & 22.6 & 16.3 & 0.0005 & 22.4 & 16.0 & 0.0083 \\
\hline Hypercholesterolemia (\%) & 60.0 & 38.0 & $<0.0001$ & 48.5 & 22.8 & $<0.0001$ \\
\hline Diabetes mellitus (\%) & 51.7 & 31.2 & $<0.0001$ & 40.7 & 11.2 & $<0.0001$ \\
\hline
\end{tabular}

Data for age and body mass index are means \pm SD.

Hospital; Reimeikyo Rehabilitation Hospital; and Yokohama General Hospital) between October 2002 and March 2005. The 1192 subjects with MI (926 men, 266 women) all underwent coronary angiography and left ventriculography. The diagnosis of MI was based on typical electrocardiographic changes and increases both in the serum activities of enzymes such as creatinine kinase, aspartate aminotransferase, and lactate dehydrogenase and in the serum concentration of troponin $\mathrm{T}$. The diagnosis was confirmed by the presence of a wall motion abnormality on left ventriculography and identification of the responsible stenosis in any of the major coronary arteries or in the left main trunk by coronary angiography.

The control subjects comprised 2291 individuals (987 men, 1304 women) who visited the outpatient clinics of participating hospitals for an annual health checkup. They had no history of CHD, peripheral arterial occlusive disease, or other atherosclerotic diseases; of ischemic or hemorrhagic stroke or other cerebral diseases; or of other thrombotic, embolic, or hemorrhagic disorders.

Subjects with MI and controls either had or did not have conventional risk factors for CHD, including hypertension (systolic blood pressure of $\geq 140 \mathrm{mmHg}$ or diastolic blood pressure of $\geq 90 \mathrm{mmHg}$, or both, or taking antihypertensive medication), hypercholesterolemia (serum total cholesterol of $\geq 5.72 \mathrm{mmol} / \mathrm{l}$ or taking lipid-lowering medication), diabetes mellitus (fasting blood glucose of $\geq 6.93 \mathrm{mmol} / \mathrm{l}$ or hemoglobin A1c of $\geq 6.5 \%$, or both, or taking antidiabetes medication), obesity (body mass index of $\geq 25 \mathrm{~kg} / \mathrm{m}^{2}$ ), or cigarette smoking ( $\geq 10$ cigarettes daily). The study protocol complied with the Declaration of Helsinki and was approved by the Committees on the Ethics of Human Research of Mie University School of Medicine, Hirosaki University School of Medicine, Gifu International Institute of Biotechnology, and participating hospitals, and written informed consent was obtained from each participant.

Selection of polymorphisms. With the use of public databases, we selected 137 candidate genes that have been characterized and were suggested to be associated with MI on the basis of a comprehensive overview of hypertension; atherosclerosis; arterial spasm; arterial aneurysm; platelet function; leukocyte, lymphocyte, and monocyte-macrophage biology; coagulation and fibrinolysis cascades; neurological factors; as well as lipid, glucose, and homocysteine metabolism and other metabolic factors. We further selected 164 polymorphisms of these genes, most located in the promoter region, exons, or splice donor or acceptor sites of introns, that might be expected to result in changes in the function or expression of the encoded protein (9).

Genotyping of polymorphisms. Venous blood $(7 \mathrm{ml})$ was collected into tubes containing $50 \mathrm{mmol} / \mathrm{l}$ EDTA (disodium salt), and genomic DNA was isolated with a kit (Genomix; Talent, Trieste, Italy). Genotypes of the 164 polymorphisms were determined (G\&G Science, Fukushima, Japan) by a method that combines the polymerase chain reaction and sequence-specific oligonucleotide probes with analysis by suspension array technology (Luminex 100 flow cytometer; Luminex, Austin, TX, USA). Detailed methodology for genotyping was described previously (10).

Statistical analysis. Clinical data were compared between subjects with MI and controls by the unpaired Student's t-test. Qualitative data were compared by the chi-square test. Allele frequencies were estimated by the gene counting method, and the chi-square test was used to identify departures from HardyWeinberg equilibrium. In the initial screen, the genotype distribution of each autosomal polymorphism was compared between subjects with MI and controls by the chi-square test ( $3 \times 2)$; for polymorphisms on the $\mathrm{X}$ chromosome, allele frequencies were compared by the chi-square test $(2 \times 2)$. Polymorphisms related $(\mathrm{P}<0.05)$ to $\mathrm{MI}$ were further examined by multivariable logistic regression analysis with adjustment for covariates (with the exception of that used for stratification of subjects), with MI as a dependent variable and independent variables including age, sex (0, woman; 1 , man), body mass index (BMI), smoking status (0, nonsmoker; 1, smoker), metabolic variables $(0$, no history of hypertension, hypercholesterolemia, or diabetes mellitus; 1 , positive history), and genotype of each polymorphism. Each genotype was assessed according to dominant, recessive, and additive (additive 1 and 2) genetic models, and the $\mathrm{P}$ value, odds ratio, and $95 \%$ confidence interval were calculated. Each genetic model 
Table II. Multivariable logistic regression analysis of polymorphisms associated with myocardial infarction in hypertensive individuals.

\begin{tabular}{|c|c|c|c|c|c|c|c|c|c|}
\hline \multirow[t]{2}{*}{ Gene } & \multirow[t]{2}{*}{ Polymorphism } & \multicolumn{2}{|c|}{ Dominant model } & \multicolumn{2}{|c|}{ Recessive model } & \multicolumn{2}{|c|}{ Additive 1 model } & \multicolumn{2}{|c|}{ Additive 2 model } \\
\hline & & $\mathrm{P}$ & $5 \% \mathrm{CI})$ & $\mathrm{P}$ & $5 \% \mathrm{CI})$ & $\mathrm{P}$ & OR $(95 \% \mathrm{CI})$ & $\mathrm{P}$ & OR $(95 \% \mathrm{CI})$ \\
\hline$I P F 1$ & $-108 / 3 \mathrm{G} \rightarrow 4 \mathrm{G}$ & 0.0005 & $0.66(0.52-0.83)$ & 0.1265 & & 0.0016 & $0.67(0.52-0.86)$ & 0.0018 & $0.64(0.48-0.85)$ \\
\hline MTHFR & $677 \mathrm{C} \rightarrow \mathrm{T}($ Ala222Val $)$ & 0.1460 & & 0.0004 & $1.59(1.23-2.05)$ & 0.8025 & & 0.0010 & $1.61(1.21-2.15)$ \\
\hline$L P L$ & $\mathrm{C} \rightarrow \mathrm{G}$ (Ser447Stop) & 0.0682 & & 0.0144 & $0.29(0.10-0.74)$ & 0.1922 & & 0.0120 & $0.28(0.10-0.72)$ \\
\hline$A C D C$ & $-11,377 \mathrm{C} \rightarrow \mathrm{G}$ & 0.0213 & $1.26(1.04-1.54)$ & 0.5943 & & 0.0107 & $1.31(1.06-1.61)$ & 0.9851 & \\
\hline$M M P 2$ & $-1306 \mathrm{C} \rightarrow \mathrm{T}$ & 0.3216 & & 0.0190 & $3.61(1.31-11.7)$ & 0.0985 & & 0.0227 & $3.49(1.26-11.3)$ \\
\hline$G P 1 B A$ & $1018 \mathrm{C} \rightarrow \mathrm{T}(\mathrm{Thr} 145 \mathrm{Met})$ & 0.0044 & $1.41(1.11-1.79)$ & 0.6002 & & 0.0025 & $1.45(1.14-1.85)$ & 0.7359 & \\
\hline CAPN10 & $4852 \mathrm{G} \rightarrow \mathrm{A}(\mathrm{SNP}-43)$ & 0.5116 & & 0.6010 & & 0.7971 & & 0.6008 & \\
\hline UTS2 & $\mathrm{G} \rightarrow \mathrm{A}($ Ser89Asn $)$ & 0.4323 & & 0.0009 & $2.26(1.40-3.68)$ & 0.8664 & & 0.0011 & $2.24(1.38-3.67)$ \\
\hline PON1 & $584 \mathrm{G} \rightarrow \mathrm{A}(\mathrm{G} \ln 192 \mathrm{Arg})$ & 0.0792 & & 0.1011 & & 0.0167 & $1.29(1.05-1.59)$ & 0.3999 & \\
\hline PLAT & $-7351 \mathrm{C} \rightarrow \mathrm{T}$ & 0.0087 & $0.77(0.63-0.94)$ & 0.1437 & & 0.0224 & $0.78(0.64-0.97)$ & 0.0506 & \\
\hline PCK1 & $-232 \mathrm{C} \rightarrow \mathrm{G}$ & 0.4300 & & 0.0261 & $1.44(1.04-1.98)$ & 0.9167 & & 0.0320 & $1.44(1.03-2.02)$ \\
\hline$F 7$ & $11,496 \mathrm{G} \rightarrow \mathrm{A}(\mathrm{Arg} 353 \mathrm{Gln})$ & 0.0212 & $0.69(0.50-0.94)$ & 0.6213 & & 0.0244 & $0.69(0.50-0.95)$ & 0.5861 & \\
\hline
\end{tabular}

OR, odds ratio; CI, confidence interval. Multivariable logistic regression analysis was performed with adjustment for age, sex, body mass index, and the prevalence of smoking, hypercholesterolemia, and diabetes mellitus. P values of $<0.005$ are shown in bold.

comprised two groups: the combined group of variant homozygotes and heterozygotes versus wild-type homozygotes for the dominant model; variant homozygotes versus the combined group of wild-type homozygotes and heterozygotes for the recessive model; heterozygotes versus wild-type homozygotes for the additive 1 model; and variant homozygotes versus wild-type homozygotes for the additive 2 model. We also performed a stepwise forward selection procedure to examine the effects of genotypes as well as of other covariates on MI. Given the multiple comparisons of genotypes with MI, we adopted the criterion of $\mathrm{P}<0.005$ for significant association. For other clinical background data, a $\mathrm{P}$ value of $<0.05$ was considered statistically significant. Statistical significance was examined by two-sided tests, and statistical analyses were performed with JMP version 5.1 software (SAS Institute, Cary, NC, USA).

\section{Results}

Association of polymorphisms with MI in the absence or presence of hypertension. Characteristics of subjects with MI and controls in the absence or presence of hypertension are shown in Table I. For hypertensive individuals, the incidence among men and the prevalence of smoking, hypercholesterolemia, and diabetes mellitus were greater, whereas age was younger, in subjects with MI than in controls. For normotensive individuals, age, incidence among men, and the prevalence of smoking, hypercholesterolemia, and diabetes mellitus were greater in subjects with MI than in controls.

The chi-square test revealed that 12 and 13 polymorphisms were related to $\mathrm{MI}$ in hypertensive and normotensive individuals, respectively (Supplementary Table I). Multivariable logistic regression analysis with adjustment for age, sex, BMI, and the prevalence of smoking, hypercholesterolemia, and diabetes mellitus revealed that the $-108 / 3 \mathrm{G} \rightarrow 4 \mathrm{G}$ polymorphism of IPF1 (dominant and additive 1 and 2 models), the $677 \mathrm{C} \rightarrow \mathrm{T}$
Table III. Effects of genotypes and other characteristics on the prevalence of myocardial infarction as determined by a stepwise forward selection procedure in hypertensive or normotensive individuals.

\begin{tabular}{lcc}
\hline Parameter & $\mathrm{P}$ & $\mathrm{R}^{2}$ \\
\hline & Hypertension $(+)$ & \\
Sex & $<0.0001$ & 0.0555 \\
Hypercholesterolemia & $<0.0001$ & 0.0450 \\
Diabetes mellitus & $<0.0001$ & 0.0200 \\
MTHFR $(T T$ versus $C C+C T)$ & 0.0003 & 0.0049 \\
IPF1 $(4 G 4 G+3 G 4 G$ versus $3 G 3 G)$ & 0.0006 & 0.0045 \\
UTS2 $(A A$ versus $G G+G A)$ & 0.0010 & 0.0042 \\
$G P 1 B A(T T+C T$ versus $C C)$ & 0.0036 & 0.0033 \\
$P L A T(T T+C T$ versus $C C)$ & 0.0119 & 0.0024 \\
LPL $(G G$ versus $C C+C G)$ & 0.0196 & 0.0021 \\
$M M P 2(T T$ versus $C C+C T)$ & 0.0203 & 0.0021 \\
$F 7(A A+G A$ versus $G G)$ & 0.0247 & 0.0019 \\
$A C D C(G G+C G$ versus $C C)$ & 0.0296 & 0.0018 \\
& Hypertension $(-)$ & \\
Sex & $<0.0001$ & 0.1385 \\
Diabetes mellitus & $<0.0001$ & 0.0641 \\
Hypercholesterolemia & $<0.0001$ & 0.0448 \\
Age & 0.0026 & 0.0056 \\
Smoking & 0.0157 & 0.0036 \\
$A K A P 10(G G$ versus $A A+A G)$ & 0.0182 & 0.0035 \\
$T N F S F(G G+A G$ versus $A A)$ & 0.0202 & 0.0034 \\
$C E T P(A A$ versus $C C+C A)$ & 0.0278 & 0.0030 \\
\hline
\end{tabular}

(Ala222Val) polymorphism of MTHFR (recessive and additive 2 models), the $1018 \mathrm{C} \rightarrow \mathrm{T}$ (Thr145Met) polymorphism of 
Table IV. Characteristics of subjects with or without hypercholesterolemia.

\begin{tabular}{|c|c|c|c|c|c|c|}
\hline \multirow[b]{2}{*}{ Characteristic } & \multicolumn{3}{|c|}{ Hypercholesterolemia (+) } & \multicolumn{3}{|c|}{ Hypercholesterolemia (-) } \\
\hline & Myocardial infarction & Controls & $\mathrm{P}$ & Myocardial infarction & Controls & $\mathrm{P}$ \\
\hline No. of subjects & 678 & 677 & & 514 & 1614 & \\
\hline Age (years) & $62.4 \pm 10.3$ & $62.8 \pm 11.0$ & 0.5310 & $65.4 \pm 10.7$ & $62.4 \pm 12.1$ & $<0.0001$ \\
\hline Sex (female/male, \%) & $27.0 / 73.0$ & $64.0 / 36.0$ & $<0.0001$ & $16.2 / 83.8$ & $54.0 / 46.0$ & $<0.0001$ \\
\hline Body mass index $\left(\mathrm{kg} / \mathrm{m}^{2}\right)$ & $24.0 \pm 3.2$ & $23.7 \pm 3.2$ & 0.1880 & $23.2 \pm 3.1$ & $23.2 \pm 3.0$ & 0.7650 \\
\hline Smoker (\%) & 21.7 & 13.2 & $<0.0001$ & 23.7 & 17.3 & 0.0016 \\
\hline Hypertension (\%) & 77.0 & 57.0 & $<0.0001$ & 67.7 & 39.0 & $<0.0001$ \\
\hline Diabetes mellitus (\%) & 50.2 & 27.9 & $<0.0001$ & 46.9 & 16.8 & $<0.0001$ \\
\hline
\end{tabular}

Data for age and body mass index are means $\pm \mathrm{SD}$.

Table V. Multivariable logistic regression analysis of polymorphisms associated with myocardial infarction in individuals without hypercholesterolemia.

\begin{tabular}{|c|c|c|c|c|c|c|c|c|c|}
\hline \multirow[t]{2}{*}{ Gene } & \multirow[t]{2}{*}{ Polymorphism } & \multicolumn{2}{|c|}{ Dominant model } & \multicolumn{2}{|c|}{ Recessive model } & \multicolumn{2}{|c|}{ Additive 1 model } & \multicolumn{2}{|c|}{ Additive 2 model } \\
\hline & & $\mathrm{P}$ & OR $(95 \% \mathrm{CI})$ & $\mathrm{P}$ & OR $(95 \% \mathrm{CI})$ & $\mathrm{P}$ & OR $(95 \% \mathrm{CI})$ & $\mathrm{P}$ & OR $(95 \% \mathrm{CI})$ \\
\hline MTHFR & $677 \mathrm{C} \rightarrow \mathrm{T}(\mathrm{Ala} 222 \mathrm{Val})$ & 0.1141 & & 0.0001 & $1.74(1.32-2.30)$ & 0.7650 & & 0.0004 & $1.78(1.30-2.45)$ \\
\hline$A G E R$ & $\mathrm{G} \rightarrow \mathrm{A}(\mathrm{Gly} 82 \mathrm{Ser})$ & 0.4782 & & 0.0065 & $0.18(0.04-0.53)$ & 0.1464 & & 0.0084 & $0.19(0.04-0.56)$ \\
\hline$A C D C$ & $-11,377 \mathrm{C} \rightarrow \mathrm{G}$ & 0.0018 & $1.43(1.14-1.79)$ & 0.3036 & & 0.0004 & $1.52(1.21-1.92)$ & 0.7174 & \\
\hline$A A C T$ & $\mathrm{G} \rightarrow \mathrm{A}($ Ala15Thr $)$ & 0.6688 & & 0.0113 & $0.73(0.57-0.93)$ & 0.2090 & & 0.3770 & \\
\hline$L P L$ & $\mathrm{C} \rightarrow \mathrm{G}$ (Ser447Stop) & 0.0143 & $0.71(0.54-0.93)$ & 0.8105 & & 0.0139 & $0.70(0.53-0.93)$ & 0.6804 & \\
\hline$F A B P 2$ & $2445 \mathrm{G} \rightarrow \mathrm{A}($ Ala54Thr $)$ & 0.0020 & $1.44(1.14-1.81)$ & 0.1131 & & 0.0064 & $1.41(1.10-1.80)$ & 0.0118 & $1.53(1.10-2.14)$ \\
\hline$I P F 1$ & $-108 / 3 \mathrm{G} \rightarrow 4 \mathrm{G}$ & 0.0017 & $0.67(0.52-0.86)$ & 0.3183 & & 0.0031 & $0.67(0.51-0.87)$ & 0.0118 & $0.67(0.49-0.92)$ \\
\hline$F 7$ & 11,496G $\rightarrow \mathrm{A}(\operatorname{Arg} 353 \mathrm{Gln})$ & 0.0072 & $0.60(0.41-0.86)$ & 0.3079 & & 0.0044 & $0.57(0.39-0.83)$ & 0.3377 & \\
\hline AKAP10 & $\mathrm{A} \rightarrow \mathrm{G}$ (Ile646Val) & 0.9564 & & 0.0026 & $2.12(1.29-3.44)$ & 0.3854 & & 0.0046 & $2.04(1.24-3.34)$ \\
\hline$A P O E$ & $4070 \mathrm{C} \rightarrow \mathrm{T}(\operatorname{Arg} 158 \mathrm{Cys})$ & 0.0833 & & 0.7404 & & 0.0992 & & 0.7390 & \\
\hline$T G F B 1$ & $-509 \mathrm{C} \rightarrow \mathrm{T}$ & 0.0325 & $0.76(0.59-0.98)$ & 0.8384 & & 0.0286 & $0.74(0.57-0.97)$ & 0.1621 & \\
\hline FLJ23476 & $\mathrm{C} \rightarrow \mathrm{A}(\operatorname{Pro55Gln})$ & 0.0389 & $0.64(0.43-0.98)$ & 0.7590 & & 0.0389 & $0.63(0.41-0.98)$ & 0.0528 & \\
\hline CETP & $-629 \mathrm{C} \rightarrow \mathrm{A}$ & 0.1022 & & 0.0183 & $1.34(1.05-1.71)$ & 0.3647 & & 0.0167 & $1.47(1.07-2.02)$ \\
\hline$F 12$ & $46 \mathrm{C} \rightarrow \mathrm{T}$ & 0.9975 & & 0.0032 & $1.40(1.12-1.76)$ & 0.3037 & & 0.2915 & \\
\hline TNFSF4 & $A \rightarrow G$ & 0.0530 & & 0.0454 & $2.54(1.00-6.28)$ & 0.1233 & & 0.0361 & $2.66(1.04-6.59)$ \\
\hline$P P A R G$ & $-681 \mathrm{C} \rightarrow \mathrm{G}$ & 0.0559 & & 0.3085 & & 0.0193 & $1.32(1.05-1.67)$ & 0.6365 & \\
\hline IRSI & $3494 \mathrm{G} \rightarrow \mathrm{A}(\mathrm{Gly} 972 \mathrm{Arg})$ & 0.3787 & & 0.6658 & & 0.5440 & & 0.6654 & \\
\hline
\end{tabular}

OR, odds ratio; CI, confidence interval. Multivariable logistic regression analysis was performed with adjustment for age, sex, body mass index, and the prevalence of smoking, hypertension, and diabetes mellitus. $\mathrm{P}$ values of $<0.005$ are shown in bold.

GPIBA (dominant and additive 1 models), and the $\mathrm{G} \rightarrow \mathrm{A}$ (Ser89Asn) polymorphism of UTS2 (recessive and additive 2 models) were significantly associated with MI in hypertensive individuals (Table II), whereas no polymorphism was significantly associated with MI in normotensive individuals (Supplementary Table II). We also performed a stepwise forward selection procedure to examine the effects of genotypes for the polymorphisms identified by the chi-square test as well as of age, sex, BMI, smoking, hypercholesterolemia, and diabetes mellitus on MI (Table III). For hypertensive individuals, sex, hypercholesterolemia, diabetes mellitus, MTHFR genotype (recessive model), IPF 1 genotype (dominant model), UTS2 genotype (recessive model), and GP1BA genotype (dominant model) were significant and independent determinants of the prevalence of MI. For normotensive individuals, sex, diabetes mellitus, hypercholesterolemia, and age significantly and independently influenced MI.

Association of polymorphisms with MI in the absence or presence of hypercholesterolemia. Characteristics of subjects with MI and controls in the absence or presence of hypercholesterolemia are shown in Table IV. For individuals with hypercholesterolemia, incidence among men and the prevalence of smoking, hypertension, and diabetes mellitus were greater 
Table VI. Effects of genotypes and other characteristics on the prevalence of myocardial infarction as determined by a stepwise forward selection procedure in individuals with or without hypercholesterolemia.

\begin{tabular}{lcc}
\hline Parameter & $\mathrm{P}$ & $\mathrm{R}^{2}$ \\
\hline & Hypercholesterolemia $(+)$ \\
Sex & $<0.0001$ & 0.1016 \\
Diabetes mellitus & $<0.0001$ & 0.0288 \\
Hypertension & $<0.0001$ & 0.0181 \\
UCP3 $(T T+C T$ versus $C C)$ & 0.0069 & 0.0039 \\
ENG $(G G$ versus $C C+C G)$ & 0.0293 & 0.0025 \\
EDNRA $(G G+A G$ versus $A A)$ & 0.0400 & 0.0022 \\
& & \\
Sex & Hypercholesterolemia $(-)$ \\
Diabetes mellitus & $<0.0001$ & 0.1045 \\
Hypertension & $<0.0001$ & 0.0541 \\
$M T H F R(T T$ versus $C C+C T)$ & $<0.0001$ & 0.0218 \\
$F A B P 2(A A+G A$ versus $G G)$ & 0.0002 & 0.0061 \\
Age & 0.0013 & 0.0044 \\
$I P F 1(4 G 4 G+3 G 4 G$ versus $3 G 3 G)$ & 0.0018 & 0.0041 \\
$A G E R(A A$ versus $G G+G A)$ & 0.0020 & 0.0041 \\
$A K A P 10(G G$ versus $A A+A G)$ & 0.0020 & 0.0041 \\
$F 7(A A+G A$ versus $G G)$ & 0.0024 & 0.0039 \\
$A C D C(G G+C G$ versus $C C)$ & 0.0025 & 0.0039 \\
$F 12(T T$ versus $C C+C T)$ & 0.0037 & 0.0036 \\
$A A C T(A A$ versus $G G+G A)$ & 0.0039 & 0.0035 \\
$L P L(G G+C G$ versus $C C)$ & 0.0089 & 0.0029 \\
$T N F S F 4(G G$ versus $A A+A G)$ & 0.0348 & 0.0019 \\
& 0.0451 & 0.0017 \\
\hline
\end{tabular}

in subjects with MI than in controls. For individuals without hypercholesterolemia, age, incidence among men, and the prevalence of smoking, hypertension, and diabetes mellitus were greater in subjects with MI than in controls. The chisquare test revealed that 8 and 17 polymorphisms were related to the prevalence of MI in individuals with or without hypercholesterolemia, respectively (Supplementary Table III).
Multivariable logistic regression analysis with adjustment for age, sex, BMI, and the prevalence of smoking, hypertension, and diabetes mellitus revealed that no polymorphism was significantly associated with MI in individuals with hypercholesterolemia (Supplementary Table IV), whereas the $677 \mathrm{C} \rightarrow \mathrm{T}$ (Ala222Val) polymorphism of MTHFR (recessive and additive 2 models), the $-11,377 \mathrm{C} \rightarrow \mathrm{G}$ polymorphism of $A C D C$ (dominant and additive 1 models), the $2445 \mathrm{G} \rightarrow \mathrm{A}$ (Ala54Thr) polymorphism of FABP2 (dominant model), the $-108 / 3 \mathrm{G} \rightarrow 4 \mathrm{G}$ polymorphism of $I P F 1$ (dominant and additive 1 models), the $11,496 \mathrm{G} \rightarrow \mathrm{A}(\mathrm{Arg} 353 \mathrm{Gln})$ polymorphism of $F 7$ (additive 1 model), the $\mathrm{A} \rightarrow \mathrm{G}$ (Ile646Val) polymorphism of $A K A P 10$ (recessive and additive 2 models), and the $46 \mathrm{C} \rightarrow \mathrm{T}$ polymorphism of $F 12$ (recessive model) were significantly associated with MI in individuals without hypercholesterolemia (Table V). We performed a stepwise forward selection procedure to examine the effects of genotypes for the polymorphisms identified by the chi-square test as well as of age, sex, BMI, smoking, hypertension, and diabetes mellitus on MI. Whereas sex, diabetes mellitus, and hypertension significantly and independently affected MI in individuals with hypercholesterolemia, sex, diabetes mellitus, hypertension, $M T H F R$ genotype (recessive model), FABP2 genotype (dominant model), age, IPFl genotype (dominant model), $A G E R$ genotype (recessive model), AKAP10 genotype (recessive model), F7 genotype (dominant model), ACDC genotype (dominant model), and F12 genotype (recessive model) were significant and independent determinants of the prevalence of MI in individuals without hypercholesterolemia (Table VI).

Association of polymorphisms with MI in the absence or presence of diabetes mellitus. Characteristics of subjects with MI and controls in the absence or presence of diabetes mellitus are shown in Table VII. For diabetic individuals, incidence among men, BMI, and the prevalence of smoking, hypertension, and hypercholesterolemia were greater, and age was younger, in subjects with MI than in controls. For nondiabetic individuals, age, incidence among men, and the prevalence of smoking, hypertension, and hypercholesterolemia were greater in subjects with MI than in controls. The chi-square test revealed that 10 and 11 polymorphisms were related to the

Table VII. Characteristics of subjects with or without diabetes mellitus.

\begin{tabular}{|c|c|c|c|c|c|c|}
\hline \multirow[b]{2}{*}{ Characteristic } & \multicolumn{3}{|c|}{ Diabetes mellitus (+) } & \multicolumn{3}{|c|}{ Diabetes mellitus (-) } \\
\hline & Myocardial infarction & Controls & $\mathrm{P}$ & Myocardial infarction & Controls & $\mathrm{P}$ \\
\hline No. of subjects & 581 & 460 & & 611 & 1831 & \\
\hline Age (years) & $63.9 \pm 9.9$ & $65.4 \pm 10.8$ & 0.0200 & $63.5 \pm 11.2$ & $61.8 \pm 11.9$ & 0.0020 \\
\hline Sex (female/male, \%) & $21.9 / 78.1$ & $48.9 / 51.1$ & $<0.0001$ & $22.7 / 77.3$ & $59.0 / 41.0$ & $<0.0001$ \\
\hline Body mass index $\left(\mathrm{kg} / \mathrm{m}^{2}\right)$ & $23.9 \pm 3.3$ & $23.5 \pm 3.6$ & 0.0280 & $23.3 \pm 2.9$ & $23.4 \pm 3.1$ & 0.7120 \\
\hline Smoker $(\%)$ & 25.0 & 19.1 & 0.0244 & 20.3 & 15.3 & 0.0051 \\
\hline Hypertension (\%) & 77.5 & 68.9 & 0.0019 & 68.7 & 38.1 & $<0.0001$ \\
\hline Hypercholesterolemia (\%) & 58.5 & 41.1 & $<0.0001$ & 55.3 & 26.6 & $<0.0001$ \\
\hline
\end{tabular}

Data for age and body mass index are means \pm SD. 
Table VIII. Multivariable logistic regression analysis of polymorphisms associated with myocardial infarction in diabetic individuals.

\begin{tabular}{|c|c|c|c|c|c|c|c|c|c|}
\hline \multirow[t]{2}{*}{ Gene } & \multirow[t]{2}{*}{ Polymorphism } & \multicolumn{2}{|c|}{ Dominant model } & \multicolumn{2}{|c|}{ Recessive model } & \multicolumn{2}{|c|}{ Additive 1 model } & \multicolumn{2}{|c|}{ Additive 2 model } \\
\hline & & $\mathrm{P}$ & OR $(95 \% \mathrm{CI})$ & $\mathrm{P}$ & OR $(95 \% \mathrm{CI})$ & $\mathrm{P}$ & OR $(95 \% \mathrm{CI})$ & $\mathrm{P}$ & OR $(95 \% \mathrm{CI})$ \\
\hline$A P O E$ & $4070 \mathrm{C} \rightarrow \mathrm{T}(\operatorname{Arg} 158 \mathrm{Cys})$ & 0.0225 & $0.56(0.34-0.92)$ & 0.7869 & & 0.0132 & $0.53(0.32-0.87)$ & 0.7881 & \\
\hline AKAP10 & $\mathrm{A} \rightarrow \mathrm{G}(\mathrm{Ile} 646 \mathrm{Val})$ & 0.5092 & & 0.1022 & & 0.8273 & & 0.0993 & \\
\hline RECQL2 & $\mathrm{T} \rightarrow \mathrm{C}($ Cys1367Arg) & 0.1191 & & 0.1434 & & 0.0634 & & 0.1562 & \\
\hline$A P O E$ & 3932T $\rightarrow$ C (Cys112Arg) & 0.0174 & $1.53(1.08-2.18)$ & 0.3247 & & 0.0091 & $1.61(1.13-2.31)$ & 0.3734 & \\
\hline$F A B P 2$ & 2445G $\rightarrow$ A (Ala54Thr) & 0.0041 & $1.47(1.13-1.92)$ & 0.1675 & & 0.0109 & $1.44(1.09-1.92)$ & 0.0318 & $1.58(1.04-2.40)$ \\
\hline MTHFR & $677 \mathrm{C} \rightarrow \mathrm{T}(\mathrm{Ala} 222 \mathrm{Val})$ & 0.7322 & & 0.0053 & $1.64(1.16-2.32)$ & 0.5199 & & 0.0280 & $1.55(1.05-2.29)$ \\
\hline PAII & A $\rightarrow \mathrm{G}$ (Tyr243Cys) & 0.4896 & & & & 0.4896 & & & \\
\hline PON1 & $\mathrm{A} \rightarrow \mathrm{G}$ (Arg160Gly) & 0.1186 & & 0.7860 & & 0.0928 & & 0.7875 & \\
\hline$I P F 1$ & $-108 / 3 \mathrm{G} \rightarrow 4 \mathrm{G}$ & 0.0220 & $0.70(0.52-0.95)$ & 0.0740 & & 0.0721 & & 0.0128 & $0.62(0.43-0.90)$ \\
\hline$A G E R$ & $\mathrm{G} \rightarrow \mathrm{A}(\mathrm{Gly} 82 \mathrm{Ser})$ & 0.4354 & & 0.0961 & & 0.2451 & & 0.1131 & \\
\hline
\end{tabular}

OR, odds ratio; CI, confidence interval. Multivariable logistic regression analysis was performed with adjustment for age, sex, body mass index, and the prevalence of smoking, hypertension, and hypercholesterolemia. $\mathrm{P}$ values of $<0.005$ are shown in bold.

Table IX. Multivariable logistic regression analysis of polymorphisms associated with myocardial infarction in nondiabetic individuals.

\begin{tabular}{|c|c|c|c|c|c|c|c|c|c|}
\hline \multirow[t]{2}{*}{ Gene } & \multirow[t]{2}{*}{ Polymorphism } & \multicolumn{2}{|c|}{ Dominant model } & \multicolumn{2}{|c|}{ Recessive model } & \multicolumn{2}{|c|}{ Additive 1 model } & \multicolumn{2}{|c|}{ Additive 2 model } \\
\hline & & $\mathrm{P}$ & OR $(95 \% \mathrm{CI})$ & $\mathrm{P}$ & OR $(95 \% \mathrm{CI})$ & $\mathrm{P}$ & OR $(95 \% \mathrm{CI})$ & $\mathrm{P}$ & OR $(95 \% \mathrm{CI})$ \\
\hline CETP & $-629 \mathrm{C} \rightarrow \mathrm{A}$ & 0.7201 & & 0.1782 & & 0.3779 & & 0.6257 & \\
\hline$L P L$ & $\mathrm{C} \rightarrow \mathrm{G}$ (Ser447Stop) & 0.1133 & & 0.2413 & & 0.1699 & & 0.2145 & \\
\hline COMT & $\mathrm{G} \rightarrow \mathrm{A}$ (Val158Met) & 0.7775 & & 0.8069 & & 0.8262 & & 0.7640 & \\
\hline MTHFR & $677 \mathrm{C} \rightarrow \mathrm{T}(\mathrm{Ala} 222 \mathrm{Val})$ & 0.0250 & $1.29(1.03-1.62)$ & 0.0416 & $1.32(1.01-1.72)$ & 0.0929 & & 0.0099 & $1.49(1.10-2.02)$ \\
\hline$T N F$ & $-863 \mathrm{C} \rightarrow \mathrm{A}$ & 0.0508 & & 0.0858 & & 0.1187 & & 0.0669 & \\
\hline$G P 1 B A$ & $1018 \mathrm{C} \rightarrow \mathrm{T}$ & 0.0102 & $1.37(1.08-1.74)$ & 0.6771 & & 0.0064 & $1.41(1.10-1.80)$ & 0.8077 & \\
\hline PON1 & $584 \mathrm{G} \rightarrow \mathrm{A}(\mathrm{G} \ln 192 \mathrm{Arg})$ & 0.2056 & & 0.0797 & & 0.0590 & & 0.2689 & \\
\hline$F A B P 2$ & 2445G $\rightarrow$ A (Ala54Thr) & 0.0279 & $1.27(1.03-1.58)$ & 0.4923 & & 0.0362 & & 0.1491 & \\
\hline IPF1 & $-108 / 3 \mathrm{G} \rightarrow 4 \mathrm{G}$ & 0.0044 & $0.70(0.55-0.90)$ & 0.6682 & & 0.0015 & $0.66(0.51-0.85)$ & 0.1073 & \\
\hline PTGS2 & $\mathrm{G} \rightarrow \mathrm{C}$ & 0.2099 & & 0.1993 & & 0.1149 & & 0.2068 & \\
\hline$F 7$ & $11,496 \mathrm{G} \rightarrow \mathrm{A}(\mathrm{Arg} 353 \mathrm{Gln})$ & 0.0072 & $0.63(0.45-0.88)$ & 0.3122 & & 0.0108 & $0.64(0.45-0.90)$ & 0.2845 & \\
\hline
\end{tabular}

OR, odds ratio; CI, confidence interval. Multivariable logistic regression analysis was performed with adjustment for age, sex, body mass index, and the prevalence of smoking, hypertension, and hypercholesterolemia. $\mathrm{P}$ values of $<0.005$ are shown in bold.

prevalence of MI in diabetic and nondiabetic individuals, respectively (Supplementary Table V). Multivariable logistic regression analysis with adjustment for age, sex, BMI, and the prevalence of smoking, hypertension, and hypercholesterolemia revealed that the $2445 \mathrm{G} \rightarrow \mathrm{A}$ (Ala54Thr) polymorphism of $F A B P 2$ (dominant model) was significantly associated with MI in diabetic individuals (Table VIII), and that the -108 / $3 \mathrm{G} \rightarrow 4 \mathrm{G}$ polymorphism of IPFI (dominant and additive 1 models) was significantly associated with $\mathrm{MI}$ in nondiabetic individuals (Table IX). A stepwise forward selection procedure was performed to examine the effects of genotypes for the polymorphisms identified by the chi-square test as well as of age, sex, BMI, smoking, hypertension, and hypercholesterolemia on MI (Table X). For diabetic individuals, sex, hypercholesterolemia, $F A B P 2$ genotype (dominant model), and MTHFR genotype (recessive model) were significant and independent determinants of the prevalence of MI. For nondiabetic individuals, sex, hypercholesterolemia, hypertension, and IPF 1 genotype (dominant model) significantly and independently affected the prevalence of MI.

Polymorphisms significantly associated with MI in both multivariable logistic regression analysis and the stepwise forward selection procedure for individuals with or without hypertension, hypercholesterolemia, or diabetes mellitus are summarized in Table XI.

\section{Discussion}

We have examined the association of 164 polymorphisms in 137 candidate genes with MI in individuals with or without 
Table X. Effects of genotypes and other characteristics on the prevalence of myocardial infarction as determined by a stepwise forward selection procedure in diabetic or nondiabetic individuals.

\begin{tabular}{lcc}
\hline Parameter & $\mathrm{P}$ & $\mathrm{R}^{2}$ \\
\hline & Diabetes mellitus $(+)$ \\
Sex & $<0.0001$ & 0.0586 \\
Hypercholesterolemia & $<0.0001$ & 0.0323 \\
$F A B P 2(A A+G A$ versus $G G)$ & 0.0033 & 0.0061 \\
MTHFR $(T T$ versus $C T+C C)$ & 0.0034 & 0.0060 \\
APOE $(C C+T C$ versus $T T)$ & 0.0154 & 0.0041 \\
IPF1 $(4 G 4 G+3 G 4 G$ versus $3 G 3 G)$ & 0.0182 & 0.0039 \\
APOE $(T T+C T$ versus $C C)$ & 0.0476 & 0.0027 \\
Hypertension & 0.0483 & 0.0027 \\
& & \\
Sex & Diabetes mellitus $(-)$ \\
Hypercholesterolemia & $<0.0001$ & 0.0912 \\
Hypertension & $<0.0001$ & 0.0670 \\
$I P F 1(4 G 4 G+3 G 4 G$ versus $3 G 3 G)$ & 0.0001 & 0.0345 \\
$F 7(G G$ versus $A G+A A)$ & 0.0055 & 0.0030 \\
Age & 0.0085 & 0.0028 \\
$G P 1 B A(T T+C T$ versus $C C)$ & 0.0169 & 0.0025 \\
$M T H F R(T T+C T$ versus $C C)$ & 0.0201 & 0.0021 \\
$F A B P 2(A A+G A$ versus $G G)$ & 0.0392 & 0.0020 \\
\hline
\end{tabular}

hypertension, hypercholesterolemia, or diabetes mellitus separately. Our data suggest that polymorphisms associated with MI may differ among individuals with different conventional risk factors for CHD. The major cause of MI is coronary atherosclerosis, which contributes to hemodynamically significant narrowing of the artery lumen and impairment of the control of vasomotor tone, with affected individuals having a propensity for plaque disruption and thrombus formation. We thus selected 137 candidate genes on the basis of a comprehensive overview of vascular biology; platelet, lymphocyte, and leukocyte function; coagulation and fibrinolysis cascades; as well as lipid, glucose, and homocysteine metabolism and other metabolic factors. Indeed, the genes found to be associated with MI may have roles in diverse aspects of the etiology of this condition, including intracellular signaling (AKAP10); vascular constriction (UTS2); platelet function $(G P 1 B A)$; the coagulation cascade ( $F 7$ and $F 12)$; lipid $(F A B P 2)$, glucose $(A C D C)$, and homocysteine $(M T H F R)$ metabolism; and insulin production (IPF1).

Among the nine polymorphisms associated with $\mathrm{MI}$ in the present study, five $(677 \mathrm{C} \rightarrow \mathrm{T}$ of $M T H F R,-108 / 3 \mathrm{G} \rightarrow 4 \mathrm{G}$ of $I P F 1,1018 \mathrm{C} \rightarrow \mathrm{T}$ of $G P 1 B A, 11,496 \mathrm{G} \rightarrow \mathrm{A}$ of $F 7,46 \mathrm{C} \rightarrow \mathrm{T}$ of $F 12$ ) have previously been shown to be associated with $\mathrm{MI}$ or $\mathrm{CHD}(9,11-14)$. The $-11,377 \mathrm{C} \rightarrow \mathrm{G}$ polymorphism of $A C D C$ has not previously been shown to be associated with MI or $\mathrm{CHD}$, but another polymorphism of this gene was associated with CHD (15). The remaining three polymorphisms $(\mathrm{G} \rightarrow \mathrm{A}$

Table XI. Summary of polymorphisms significantly $(\mathrm{P}<0.005)$ associated with myocardial infarction as determined by multivariable logistic regression analysis and a stepwise forward selection procedure.

\begin{tabular}{|c|c|c|c|c|}
\hline Risk factor & Gene & Polymorphism & Risk allele & Function \\
\hline \multirow[t]{4}{*}{ Hypertension (+) } & MTHFR & $677 \mathrm{C} \rightarrow \mathrm{T}(\mathrm{Ala} 222 \mathrm{Val})$ & $\mathrm{T}$ & Enzyme that regulates methylation of homocysteine \\
\hline & $I P F 1$ & $-108 / 3 \mathrm{G} \rightarrow 4 \mathrm{G}$ & $3 \mathrm{G}$ & $\begin{array}{l}\text { Protein that regulates the insulin gene in } \beta \text { cells and } \\
\text { development of the pancreas }\end{array}$ \\
\hline & UTS2 & $\mathrm{G} \rightarrow \mathrm{A}($ Ser89Asn $)$ & A & $\begin{array}{l}\text { Peptide that has potent vasoconstrictive and cardiac } \\
\text { inotropic and hypertropic effects }\end{array}$ \\
\hline & $G P 1 B A$ & $1018 \mathrm{C} \rightarrow \mathrm{T}(\mathrm{Thr} 145 \mathrm{Met})$ & $\mathrm{T}$ & Platelet surface receptor for von Willebrand factor \\
\hline \multicolumn{5}{|l|}{ Hypertension (-) } \\
\hline \multicolumn{5}{|l|}{ Hypercholesterolemia (+) } \\
\hline \multirow[t]{7}{*}{ Hypercholesterolemia (-) } & MTHFR & $677 \mathrm{C} \rightarrow \mathrm{T}(\mathrm{Ala} 222 \mathrm{Val})$ & $\mathrm{T}$ & See above \\
\hline & $F A B P 2$ & $2445 \mathrm{G} \rightarrow \mathrm{A}($ Ala54Thr $)$ & A & $\begin{array}{l}\text { Intracellular protein that contributes to absorption and } \\
\text { transport of long-chain fatty acids }\end{array}$ \\
\hline & $I P F 1$ & $-108 / 3 \mathrm{G} \rightarrow 4 \mathrm{G}$ & $3 \mathrm{G}$ & See above \\
\hline & $A K A P 10$ & $\mathrm{~A} \rightarrow \mathrm{G}(\mathrm{Ile} 646 \mathrm{Val})$ & G & $\begin{array}{l}\text { A-kinase anchor protein that directs subcellular } \\
\text { localization of protein kinase A }\end{array}$ \\
\hline & $F 7$ & $11,496 \mathrm{G} \rightarrow \mathrm{A}(\mathrm{Arg} 353 \mathrm{Gln})$ & $\mathrm{G}$ & $\begin{array}{l}\text { Factor that, with tissue factor, accelerates conversion of } \\
\text { prothrombin to thrombin }\end{array}$ \\
\hline & $A C D C$ & $-11,377 \mathrm{C} \rightarrow \mathrm{G}$ & G & Adipokine that regulates glucose and lipid metabolism \\
\hline & $F 12$ & $46 \mathrm{C} \rightarrow \mathrm{T}$ & $\mathrm{T}$ & Serine protease that activates factor XI and prekallikrein \\
\hline Diabetes mellitus (+) & $F A B P 2$ & $2445 \mathrm{G} \rightarrow \mathrm{A}(\mathrm{Ala54Thr})$ & A & See above \\
\hline Diabetes mellitus (-) & IPF1 & $-108 / 3 \mathrm{G} \rightarrow 4 \mathrm{G}$ & $3 \mathrm{G}$ & See above \\
\hline
\end{tabular}


of UTS2, $2445 \mathrm{G} \rightarrow \mathrm{A}$ of $F A B P 2, \mathrm{~A} \rightarrow \mathrm{G}$ of $A K A P 10$ ) have not previously been associated with MI or CHD.

Interactions between gene polymorphisms and conventional coronary risk factors may be important in the development of MI. Our observations suggest that polymorphisms associated with MI may differ among individuals with or without hypertension, hypercholesterolemia, or diabetes mellitus, although the underlying mechanisms responsible for these differences remain to be elucidated. Given that the effects of single polymorphisms on the development of MI are likely to be small, the association between a given polymorphism and the prevalence of MI might be influenced by the absence or presence of conventional coronary risk factors. Furthermore, conventional risk factors, such as hypertension, hypercholesterolemia, and diabetes mellitus, may themselves have genetic components and these components may interact with gene polymorphisms associated with MI.

The 677C $\rightarrow T$ (Ala222 Val) polymorphism of the 5,10methylenetetrahydrofolate reductase gene (MTHFR). Homocysteine is a sulfur-containing amino acid that plays a pivotal role in methionine metabolism. 5,10-Methylenetetrahydrofolate reductase (MTHFR) catalyzes the reduction of 5,10-methylenetetrahydrofolate to 5-methylenetetrahydrofolate, a reaction that provides a substrate for the methylation of homocysteine to methionine catalyzed by methionine synthase. Individuals with the $\mathrm{T}$ variant of the $677 \mathrm{C} \rightarrow \mathrm{T}$ (Ala222Val) polymorphism of MTHFR manifest reduced enzyme activity and higher homocysteine levels compared with those without it (16-18). Association of this polymorphism with CHD or MI has been described $(11,19,20)$. Other studies, however, did not support such an association $(18,21,22)$. These apparently contradictory results are attributable, at least in part, to differences in intake of folate and other B vitamins (23). A meta-analysis of the association of the $677 \mathrm{C} \rightarrow \mathrm{T}$ polymorphism of $M T H F R$ with the risk of CHD in 11,162 cases and 12,758 controls from 40 studies revealed that individuals with the $T T$ genotype had an odds ratio of 1.16 for CHD compared with those with the $C C$ genotype (24). Another meta-analysis of the association of the $677 \mathrm{C} \rightarrow \mathrm{T}$ polymorphism of MTHFR with CHD in 26,000 cases and 31,183 controls from 80 studies yielded an overall odds ratio of 1.14 for the $T T$ genotype versus the $C C$ genotype; odds ratios for Europe, Australia, and North America were approximately 1.0, whereas those for the Middle East and Asia were 2.61 and 1.23, respectively (25). These results indicate that the $677 \mathrm{C} \rightarrow \mathrm{T}$ polymorphism of $M T H F R$ is associated with CHD in the Middle East and Asia, but not in Europe, North America, or Australia, with this geographic variability possibly reflecting higher folate intake in the latter regions (25). These previous observations are consistent with our present results showing that the $677 \mathrm{C} \rightarrow \mathrm{T}$ (Ala222Val) polymorphism of MTHFR was associated with the prevalence of MI in Japanese individuals with hypertension and in those without hypercholesterolemia, with the $T T$ genotype being a risk factor for this condition.

The $-108 / 3 G \rightarrow 4 G$ polymorphism of the insulin promoter factor 1 gene (IPF1). Insulin promoter factor 1 (IPF1) is a homeodomain-containing protein that is a key regulator of the insulin gene in pancreatic $\beta$ cells $(26,27)$ and plays an important role in development of the pancreas $(28,29)$. IPF1deficient mice thus selectively lack the pancreas at birth (28), and a patient with pancreatic agenesis and insulin-deficient diabetes was found to have a single nucleotide deletion in codon 63 of IPF1 that caused a frameshift in the transactivation domain (29). A $3 \mathrm{G} \rightarrow 4 \mathrm{G}$ polymorphism of IPF1 was identified $108 \mathrm{bp}$ upstream of the translation start site in the Japanese population but was found not to be related to the prevalence of type 2 diabetes mellitus (30). Our present results indicate that the $-108 / 3 \mathrm{G} \rightarrow 4 \mathrm{G}$ polymorphism of IPF1 was associated with $\mathrm{MI}$ in hypertensive individuals, in individuals without hypercholesterolemia, and in those without diabetes mellitus, with the $4 \mathrm{G}$ allele protecting against this condition. Although the underlying molecular mechanism remains to be determined, this association might be attributable to an alteration in insulin metabolism.

The $G \rightarrow A$ (Ser89Asn) polymorphism of the urotensin II gene (UTS2). The cyclic undecapeptide urotensin II and its highaffinity $\mathrm{G}$ protein-coupled receptor, GPR14, are both expressed within the cardiovascular system, including vascular smooth muscle as well as the endothelium and myocardium, and they are thought to contribute to the physiological regulation of cardiovascular homeostasis (31). In vitro studies have suggested that urotensin II participates in the control of vascular remodeling by stimulating smooth muscle proliferation and fibroblast-mediated collagen deposition $(32,33)$. These observations thus further suggest that urotensin II may play a role in the etiology of atherosclerosis. Whereas little expression of urotensin II was apparent in any cell type in normal human coronary arteries, endothelial expression of this peptide was increased in coronary atherosclerotic lesions (34). The peptide was especially abundant in endothelial cells of lesions with subendothelial inflammation or fibro-fatty lesions, and it was also detected in myointimal cells and foam cells of such lesions, consistent with a role for urotensin II in the pathogenesis of coronary atherosclerosis (34). We have now shown that the $\mathrm{G} \rightarrow \mathrm{A}$ (Ser89Asn) polymorphism of UTS2 was associated with the prevalence of MI in hypertensive individuals, with the $A$ (Asn) allele representing a risk factor for this condition. Whereas the $A$ (Asn) allele has been associated with an increased risk of type 2 diabetes mellitus (35), the relation of this polymorphism to MI has not previously been described.

The $1018 C \rightarrow T$ (Thr145Met) polymorphism of the glycoprotein $I b$, platelet, a polypeptide gene (GPIBA). The glycoprotein IbIX-V complex is the major platelet surface receptor for von Willebrand factor (36). This complex plays a key role in the adhesion of platelets to injured vascular subendothelium and mediates shear stress-induced platelet activation, suggesting that it might also contribute to the development of thrombosis (37). The $1018 \mathrm{C} \rightarrow \mathrm{T}$ (Thr145Met) polymorphism of GP1BA was previously shown to be associated with CHD (12) or with acute MI or sudden cardiac death (38), with the $T$ allele being a risk factor for these conditions. These previous observations are consistent with our present results showing that the $1018 \mathrm{C} \rightarrow \mathrm{T}$ (Thr145Met) polymorphism was associated with MI in hypertensive individuals, with the $T$ allele representing a risk factor for this condition. 
The $2445 G \rightarrow A$ (Ala54Thr) polymorphism of the fatty acidbinding protein 2 gene ( $F A B P 2)$. Fatty acid-binding protein 2 (FABP2) is an intracellular protein that is expressed only in the columnar absorptive epithelial cells of the small intestine. It contains a single ligand binding site that has a high affinity for saturated or unsaturated fatty acids, and it contributes to the absorption and intracellular transport of long-chain fatty acids (39). The product of the $A$ (Thr) allele of the $2445 \mathrm{G} \rightarrow \mathrm{A}$ (Ala54Thr) polymorphism of $F A B P 2$ exhibits a greater affinity for long-chain fatty acids in vitro than does that of the $G$ (Ala) allele (40). In addition, individuals with the $A$ allele were shown to be more insulin resistant and more obese than were those with the $G$ allele $(40,41)$. The $A$ allele was also found to be associated with higher plasma levels of low density lipoprotein-cholesterol (42) or with metabolic syndrome and dyslipidemia (43). The $2445 \mathrm{G} \rightarrow \mathrm{A}$ polymorphism was previously associated with a parental history of stroke, but not with that of MI, in a population in Sweden (44). It was not associated with CHD in a Finnish study (45) or in the Framingham Offspring Study (42). However, the population size of these studies was small. Our results indicate that the $2445 \mathrm{G} \rightarrow \mathrm{A}$ (Ala54Thr) polymorphism of $F A B P 2$ was associated with $\mathrm{MI}$ in individuals without hypercholesterolemia and in diabetic individuals, with the $A$ (Thr) allele representing a risk factor for this condition. The effects of this polymorphism on both insulin resistance and lipid metabolism may account for its association with MI.

The $A \rightarrow G$ (Ile646Val) polymorphism of the A-kinase anchor protein 10 gene (AKAP10). The $\mathrm{A} \rightarrow \mathrm{G}$ (Ile646Val) polymorphism of $A K A P 10$ has been shown to be related to age, with the frequency of the $G$ (Val) allele being lower in older (>60 years) than younger (18 to 39 years) individuals (46). Analysis of an independent cohort indicated that the $G$ variant was associated with a decrease in the P-R interval of the electrocardiogram. The Ile646Val polymorphism is located in the A-kinase binding domain of AKAP10, and an in vitro binding assay revealed that the extent of binding to the RI $\alpha$ isoform of protein kinase A was approximately three-fold greater for the Val variant than for the Ile variant (46). This change in affinity affected the subcellular distribution of an ectopically expressed RI $\alpha$ isoform. These observations suggest that a change in the subcellular localization of the RI $\alpha$ isoform of protein kinase A caused by variation in AKAP10 may be related to cardiac dysfunction (46). Our present results show that the $\mathrm{A} \rightarrow \mathrm{G}$ (Ile646Val) polymorphism of $A K A P 10$ was associated with the prevalence of MI in individuals without hypercholesterolemia, with the $G$ (Val) allele being a risk factor for this condition. The underlying molecular mechanism of this association remains to be elucidated.

The 11,496G $\rightarrow$ A (Arg353Gln) polymorphism of the coagulation factor VII gene (F7). Factor VII initiates coagulation in conjunction with tissue factor (TF). Whereas, under normal conditions, TF is not exposed to the bloodstream, vessel injury results in the exposure of this protein to circulating factor VII. The binding of TF to factor VII triggers the conversion of the latter to the active factor VIIa by various proteases including thrombin (factor IIa), factor $\mathrm{Xa}$, and the factor VIIa-TF complex itself (http://www.answers.com/topic/factor- vii). The $11,496 \mathrm{G} \rightarrow \mathrm{A}(\mathrm{Arg} 353 \mathrm{Gln})$ polymorphism of $F 7$ was shown to be related to the plasma level of factor VII $(13,47)$, with individuals with the $A A$ genotype having lower levels of both factor VII antigen and factor VII clotting activity compared with those with the $G G$ genotype. This polymorphism was also previously associated with MI, with subjects with the $A A$ genotype having a reduced risk for this condition (13). The $A$ allele of this polymorphism was also found to be protective against acute $\mathrm{MI}$ in patients with CHD (48). Our results now show that the $11,496 \mathrm{G} \rightarrow \mathrm{A}$ (Arg353Gln) polymorphism of $F 7$ was associated with the prevalence of $\mathrm{MI}$ in individuals without hypercholesterolemia, with the $A$ allele protecting against this condition, consistent with the previous observations $(13,48)$. However, other studies have failed to detect a relation between this polymorphism and MI $(49,50)$. A meta-analysis of 1258 cases and 1316 controls showed that the combined group of $G A$ and $A A$ genotypes had a reduced risk for CHD (odds ratio, 0.78), with the $A A$ genotype being even more protective (odds ratio, 0.53 ) against this condition (51). Another recent meta-analysis, however, showed no significant overall association of this polymorphism with CHD (52). The relation of this $F 7$ polymorphism to CHD or MI thus requires further evaluation with large populations of various ethnic groups.

The $-11,377 C \rightarrow G$ polymorphism of the adipocyte, $C 1 Q$, and collagen domain containing gene $(A C D C)$. Adiponectin is an important modulator of insulin sensitivity and resistance. Plasma levels of adiponectin were found to be lower in individuals with type 2 diabetes mellitus or CHD than in control subjects $(53,54)$. Experimental studies have suggested that adiponectin might play a role in atherosclerosis. Neointimal thickening and proliferation of vascular smooth cells in injured arteries were thus found to be more pronounced in adiponectin-deficient mice than in control animals (55). Genetic epidemiological studies have also implicated the adiponectin gene $(A C D C)$ in susceptibility to insulin resistance and type 2 diabetes mellitus $(56,57)$. Furthermore, the Ile164Thr polymorphism of $A C D C$ was shown to be associated with metabolic syndrome and with CHD in a Japanese population (15). These observations implicate ACDC as a candidate susceptibility gene for CHD and MI. We have now shown that the $-11,377 \mathrm{C} \rightarrow \mathrm{G}$ polymorphism of $A C D C$, which was previously found to be associated with type 2 diabetes mellitus (57), was associated with the prevalence of MI in individuals without hypercholesterolemia, with the $G$ allele representing a risk factor for this condition. The effects of this polymorphism on both insulin resistance and predisposition to diabetes mellitus may account for its association with MI.

The 46C $\rightarrow$ T polymorphism of the coagulation factor XII gene (F12). The serine protease factor XII is the first coagulation factor in the intrinsic pathway of the coagulation cascade. It is activated during the contact phase of coagulation in a system consisting of factor XII, prekallikrein, factor XI, and highmolecular-weight kininogen. This system is initiated by the conversion of factor XII to its activated form, factor XIIa, which then activates factor XI and prekallikrein, thereby generating the potential for dissemination of reactions along several pathways concerned with coagulation and fibrinolysis 
as well as with tissue defense and repair (58). The $46 \mathrm{C} \rightarrow \mathrm{T}$ polymorphism of $F 12$ was shown to be related to the plasma concentration and coagulation activity of factor XII, with the $T$ allele being associated with a reduced concentration and activity $(14,58,59)$. The $T T$ genotype of this polymorphism was also found to be protective against acute coronary syndrome in patients with CHD (60). In contrast, other studies showed that the $T T$ genotype of this $F 12$ polymorphism was associated with an increased risk of CHD (58) or MI (14). We have now shown that the $46 \mathrm{C} \rightarrow \mathrm{T}$ polymorphism of $F 12$ was associated with the prevalence of MI in individuals without hypercholesterolemia, with the $T$ allele representing a risk factor for this condition, consistent with the latter two studies $(14,58)$. Reduced fibrinolysis as a consequence of a lower plasma concentration of factor XII (58) and an increased proinflammatory state related to a higher level of C-reactive protein (14) in individuals with the $T$ allele might underlie a higher risk of CHD or MI conferred by this polymorphism.

There are several limitations to the present study. Given the multiple comparisons of genotypes with MI, we adopted a strict criterion of $\mathrm{P}<0.005$ for statistical significance of association. However, we are not able to exclude completely the possible occurrence of false positives. It is also possible that one or more of the polymorphisms associated with MI in our study are in linkage disequilibrium with polymorphisms of other nearby genes that are actually responsible for the development of this condition. Finally, the functional relevance of the identified polymorphisms to gene transcription or to protein structure or function was not determined in the present study.

In conclusion, the present observations suggest that nine different polymorphisms are associated with MI in individuals with or without hypertension, hypercholesterolemia, or diabetes mellitus. Given that the absence or presence of conventional coronary risk factors may affect the association of gene polymorphisms with MI, stratification of subjects on the basis of such risk factors may be important in order to achieve personalized prevention of MI with the use of genetic information. Given that multiple variants, each having a small effect, will ultimately be found to be responsible for a large fraction of the genetic component of MI, further identification of MI susceptibility genes will allow more accurate assessment of the genetic component of this condition.

\section{Acknowledgments}

This study was supported in part by a Grant-in-Aid for Scientific Research from the Ministry of Education, Culture, Sports, Science, and Technology of Japan (no. 15209021, to Y.Y) as well as by a grant from Gifu Prefectural Science and Technology Promotion Center (to Y.Y.).

\section{References}

1. Thom T, Haase N, Rosamond W, et al: Heart disease and stroke statistics-2006 update: a report from the American Heart Association Statistics Committee and Stroke Statistics Subcommittee. Circulation 113: e85-e151, 2006.

2. Collins FS: Shattuck Lecture-Medical and societal consequences of the Human Genome Project. N Engl J Med 341: 28-37, 1999.

3. Weiss EJ, Bray PF, Tayback M, et al: A polymorphism of a platelet glycoprotein receptor as an inherited risk factor for coronary thrombosis. N Engl J Med 334: 1090-1094, 1996.
4. Kuivenhoven JA, Jukema JW, Zwinderman AH, et al: The role of a common variant of the cholesterol ester transfer protein gene in the progression of coronary atherosclerosis. $\mathrm{N}$ Engl $\mathrm{J}$ Med 338: 86-93, 1998.

5. Yamada Y, Izawa H, Ichihara S, et al: Prediction of the risk of myocardial infarction from polymorphisms in candidate genes. N Engl J Med 347: 1916-1923, 2002.

6. Ozaki K, Ohnishi Y, Iida A, et al: Functional SNPs in the lymphotoxin- $\alpha$ gene that are associated with susceptibility to myocardial infarction. Nat Genet 32: 650-654, 2002.

7. Ozaki K, Inoue K, Sato $\mathrm{H}$, et al: Functional variation in $L G A L S 2$ confers risk of myocardial infarction and regulates lymphotoxin- $\alpha$ secretion in vitro. Nature 429: 72-75, 2004.

8. Helgadottir A, Manolescu A, Helgason A, et al: A variant of the gene encoding leukotriene A4 hydrolase confers ethnicityspecific risk of myocardial infarction. Nat Genet 38: 68-74, 2006.

9. Yamada Y, Matsuo H, Segawa T, et al: Assessment of genetic risk for myocardial infarction. Thromb Haemost 96: 220-227, 2006.

10. Itoh Y, Mizuki N, Shimada T, et al: High throughput DNA typing of HLA-A, -B, -C and -DRB1 loci by a PCR-SSOPLuminex method in the Japanese population. Immunogenetics 57: 717-729, 2005.

11. Morita H, Taguchi J, Kurihara H, et al: Genetic polymorphism of 5,10-methylenetetrahydrofolate reductase (MTHFR) as a risk factor for coronary artery disease. Circulation 95: 2032-2036, 1997.

12. Murata M, Matsubara Y, Kawano K, et al: Coronary artery disease and polymorphisms in a receptor mediating shear stressdependent platelet activation. Circulation 96: 3281-3286, 1997.

13. Iacoviello L, Di Castelnuovo A, De Knijff P, et al: Polymorphisms in the coagulation factor VII gene and the risk of myocardial infarction. N Engl J Med 338: 79-85, 1998.

14. Roldan V, Corral J, Marin F, Pineda J, Vicente V and GonzalezConejero R: Synergistic association between hypercholesterolemia and the C46T factor XII polymorphism for developing premature myocardial infarction. Thromb Haemost 94: 1294-1299, 2005.

15. Ohashi K, Ouchi N, Kihara S, et al: Adiponectin I164T mutation is associated with the metabolic syndrome and coronary artery disease. J Am Coll Cardiol 43: 1195-1200, 2004.

16. Deloughery TG, Evans A, Sadeghi A, et al: Common mutation in methylenetetrahydrofolate reductase. Correlation with homocysteine metabolism and late-onset vascular disease. Circulation 94: 3074-3078, 1996.

17. Ma J, Stampfer MJ, Hennekens CH, et al: Methylenetetrahydrofolate reductase polymorphism, plasma folate, homocysteine, and risk of myocardial infarction in US physicians. Circulation 94: 2410-2416, 1996.

18. Schwartz SM, Siscovick DS, Malinow MR, et al: Myocardial infarction in young women in relation to plasma total homocysteine, folate, and a common variant in the methylenetetrahydrofolate reductase gene. Circulation 96: 412-417, 1997.

19. Gallagher PM, Meleady R, Shields DC, et al: Homocysteine and risk of premature coronary heart disease. Evidence for a common gene mutation. Circulation 94: 2154-2158, 1996.

20. Mager A, Lalezari S, Shohat T, et al: Methylenetetrahydrofolate reductase genotypes and early-onset coronary artery disease. Circulation 100: 2406-2410, 1999.

21. Schmitz C, Lindpaintner K, Verhoef P, Gaziano JM and Buring J: Genetic polymorphism of methylenetetrahydrofolate reductase and myocardial infarction: a case-control study. Circulation 94: 1812-1814, 1996.

22. Folsom AR, Nieto FJ, McGovern PG, et al: Prospective study of coronary heart disease incidence in relation to fasting total homocysteine, related genetic polymorphisms, and B vitamins: the Atherosclerosis Risk in Communities (ARIC) Study. Circulation 98: 204-210, 1998.

23. Verhoef P, Rimm EB, Hunter DJ, et al: A common mutation in the methylenetetrahydrofolate reductase gene and risk of coronary heart disease: results among U.S. men. J Am Coll Cardiol 32: 353-359, 1998.

24. Klerk M, Verhoef P, Clarke R, et al: MTHFR $677 \mathrm{C} \rightarrow \mathrm{T}$ polymorphism and risk of coronary heart disease: a meta-analysis. JAMA 288: 2023-2031, 2002.

25. Lewis SJ, Ebrahim S and Smith GD: Meta-analysis of MTHFR $677 \mathrm{C} \rightarrow \mathrm{T}$ polymorphism and coronary heart disease: Does totality of evidence support causal role for homocysteine and preventive potential of folate? Br Med J 331: 1053-1056, 2005.

26. Ohlsson H, Karlsson K and Edlund T: IPF1, a homeodomaincontaining transactivator of the insulin gene. EMBO J 12: 4251-4259, 1993. 
27. Inoue $\mathrm{H}$, Riggs $\mathrm{AC}$, Tanizawa $\mathrm{Y}$, et al: Isolation, characterization, and chromosomal mapping of the human insulin promoter factor 1 (IPF-1) gene. Diabetes 45: 789-794, 1996

28. Jonsson J, Carlsson L, Edlund $\mathrm{T}$ and Edlund $\mathrm{H}$ : Insulin promoter-factor 1 is required for pancreas development in mice. Nature 371: 606-609, 1994.

29. Stoffers DA, Zinkin NT, Stanojevic V, Clarke WL and Habener JF: Pancreatic agenesis attributable to a single nucleotide deletion in the human IPF1 gene coding sequence. Nat Genet 15: 106-110, 1997.

30. Yamada K, Yuan X, Ishiyama S, et al: Identification of a single nucleotide insertion polymorphism in the upstream region of the insulin promoter factor-1 gene: an association study with diabetes mellitus. Diabetologia 41: 603-605, 1998.

31. Douglas SA and Ohlstein EH: Human urotensin-II, the most potent mammalian vasoconstrictor identified to date, as a therapeutic target for the management of cardiovascular disease. Trends Cardiovasc Med 10: 229-237, 2000.

32. Watanabe T, Pakala R, Katagiri T and Benedict CR: Synergistic effect of urotensin II with mildly oxidized LDL on DNA synthesis in vascular smooth muscle cells. Circulation 104: 16-18, 2001.

33. Tzanidis A, Hannan RD, Thomas WG, et al: Direct actions of urotensin II on the heart: implications for cardiac fibrosis and hypertrophy. Circ Res 93: 246-253, 2003.

34. Hassan GS, Douglas SA, Ohlstein EH and Giaid A: Expression of urotensin-II in human coronary atherosclerosis. Peptides 26: 2464-2472, 2005.

35. Wenyi Z, Suzuki S, Hirai M, et al: Role of urotensin II gene in genetic susceptibility to Type 2 diabetes mellitus in Japanese subjects. Diabetologia 46: 972-976, 2003.

36. Lopez JA, Chung DW, Fujikawa K, Hagen FS, Davie EW and Roth GJ: The alpha and beta chains of human platelet glycoprotein $\mathrm{Ib}$ are both transmembrane proteins containing a leucine-rich amino acid sequence. Proc Natl Acad Sci USA 85: 2135-2139, 1988.

37. Andrews RK, Shen Y, Gardiner EE, Dong JF, Lopez JA and Berndt MC: The glycoprotein Ib-IX-V complex in platelet adhesion and signaling. Thromb Haemost 82: 357-364, 1999.

38. Mikkelsson J, Perola M, Penttila A and Karhunen PJ: Platelet glycoprotein Ib $\alpha$ HPA-2 Met/VNTR B haplotype as a genetic predictor of myocardial infarction and sudden cardiac death. Circulation 104: 876-880, 2001.

39. Lowe JB, Sacchettini JC, Laposata M, McQuillan JJ and Gordon JI: Expression of rat intestinal fatty acid-binding protein in Escherichia coli. Purification and comparison of ligand binding characteristics with that of Escherichia coli-derived rat liver fatty acid-binding protein. J Biol Chem 262: 5931-5937, 1987.

40. Baier LJ, Sacchettini JC, Knowler WC, et al: An amino acid substitution in the human intestinal fatty acid binding protein is associated with increased fatty acid binding, increased fat oxidation, and insulin resistance. J Clin Invest 95: 1281-1287, 1995.

41. Yamada K, Yuan X, Ishiyama S, et al: Association between Ala54Thr substitution of the fatty acid-binding protein 2 gene with insulin resistance and intra-abdominal fat thickness in Japanese men. Diabetologia 40: 706-710, 1997.

42. Galluzzi JR, Cupples LA, Otvos JD, Wilson PW, Schaefer EJ and Ordovas JM: Association of the A/T54 polymorphism in the intestinal fatty acid binding protein with variations in plasma lipids in the Framingham Offspring Study. Atherosclerosis 159: 417-424, 2001 .

43. Guettier JM, Georgopoulos A, Tsai MY, et al: Polymorphisms in the fatty acid-binding protein 2 and apolipoprotein $\mathrm{C}$-III genes are associated with the metabolic syndrome and dyslipidemia in a South Indian population. J Clin Endocrinol Metab 90: 1705-1711, 2005.
44. Carlsson M, Orho-Melander O, Hedenbro J, Almgren P and Groop LC: The T54 allele of the intestinal fatty acid-binding protein 2 is associated with a parental history of stroke. J Clin Endocrinol Metab 85: 2801-2804, 2000

45. Saarinen L, Pulkkinen A, Kareinen A, Heikkinen S, Lehto S and Laakso M: Variants of the fatty acid-binding protein 2 gene are not associated with coronary heart disease in nondiabetic subjects and in patients with NIDDM. Diabetes Care 21: 849-850, 1998.

46. Kammerer S, Burns-Hamuro LL, Ma Y, et al: Amino acid variant in the kinase binding domain of dual-specific A kinaseanchoring protein 2: a disease susceptibility polymorphism. Proc Natl Acad Sci USA 100: 4066-4071, 2003.

47. Green F, Kelleher C, Wilkes H, Temple A, Meade T and Humphries S: A common genetic polymorphism associated with lower coagulation factor VII levels in healthy individuals. Arterioscler Thromb 11: 540-546, 1991.

48. Girelli D, Russo C, Ferraresi P, et al: Polymorphisms in the factor VII gene and the risk of myocardial infarction in patients with coronary artery disease. N Engl J Med 343: 774-780, 2000 .

49. Ardissino D, Mannucci PM, Merlini PA, et al: Prothrombotic genetic risk factors in young survivors of myocardial infarction. Blood 94: 46-51, 1999.

50. Atherosclerosis, Thrombosis, and Vascular Biology Italian Study Group: No evidence of association between prothrombotic gene polymorphisms and the development of acute myocardial infarction at a young age. Circulation 107: 1117-1122, 2003.

51. $\mathrm{Wu} \mathrm{AH}$ and Tsongalis GJ: Correlation of polymorphisms to coagulation and biochemical risk factors for cardiovascular diseases. Am J Cardiol 87: 1361-1366, 2001.

52. Ye Z, Liu EH, Higgins JP, et al: Seven haemostatic gene polymorphisms in coronary disease: meta-analysis of 66,155 cases and 91,307 controls. Lancet 367: 651-658, 2006.

53. Hotta K, Funahashi T, Arita Y, et al: Plasma concentrations of a novel, adipose-specific protein, adiponectin, in type 2 diabetic patients. Arterioscler Thromb Vasc Biol 20: 1595-1599, 2000.

54. Kumada M, Kihara S, Sumitsuji S, et al: Coronary artery disease. Association of hypoadiponectinemia with coronary artery disease in men. Arterioscler Thromb Vasc Biol 23: 85-89, 2003.

55. Kubota N, Terauchi Y, Yamauchi T, et al: Disruption of adiponectin causes insulin resistance and neointimal formation. J Biol Chem 277: 25863-25866, 2002.

56. Kondo H, Shimomura I, Matsukawa Y, et al: Association of adiponectin mutation with type 2 diabetes: a candidate gene for the insulin resistance syndrome. Diabetes 51: 2325-2328, 2002.

57. Vasseur F, Helbecque N, Dina C, et al: Single-nucleotide polymorphism haplotypes in the both proximal promoter and exon 3 of the APM1 gene modulate adipocyte-secreted adiponectin hormone levels and contribute to the genetic risk for type 2 diabetes in French Caucasians. Hum Mol Genet 11: 2607-2614, 2002.

58. Zito F, Lowe GD, Rumley A, McMahon AD and Humphries SE Association of the factor XII $46 \mathrm{C}>\mathrm{T}$ polymorphism with risk of coronary heart disease (CHD) in the WOSCOPS study. Atherosclerosis 165: 153-158, 2002.

59. Zito F, Drummond F, Bujac SR, et al: Epidemiological and genetic associations of activated factor XII concentration with factor VII activity, fibrinopeptide A concentration, and risk of coronary heart disease in men. Circulation 102: 2058-2062, 2000

60. Endler G, Mannhalter C, Sunder-Plassmann H, et al: Homozygosity for the $\mathrm{C} \rightarrow \mathrm{T}$ polymorphism at nucleotide 46 in the 5 ' untranslated region of the factor XII gene protects from development of acute coronary syndrome. Br J Haematol 115: 1007-1009, 2001. 
Supplementary Table I. Polymorphisms related to myocardial infarction in individuals with or without hypertension as determined by the chi-square test.

\begin{tabular}{|c|c|c|c|c|c|}
\hline \multicolumn{3}{|c|}{ Hypertension (+) } & \multicolumn{3}{|c|}{ Hypertension (-) } \\
\hline Gene & Polymorphism & $\mathrm{P}$ & Gene & Polymorphism & $\mathrm{P}$ \\
\hline IPF1 & $-108 / 3 \mathrm{G} \rightarrow 4 \mathrm{G}$ & 0.0006 & $G P X 1$ & $\mathrm{C} \rightarrow \mathrm{T}$ (Pro198Leu) & 0.0034 \\
\hline MTHFR & $677 \mathrm{C} \rightarrow \mathrm{T}(\mathrm{Ala} 222 \mathrm{Val})$ & 0.0048 & PTGS2 & $\mathrm{G} \rightarrow \mathrm{C}$ & 0.0048 \\
\hline$L P L$ & $\mathrm{C} \rightarrow \mathrm{G}$ (Ser447Stop) & 0.0065 & $T N F$ & $-850 \mathrm{C} \rightarrow \mathrm{T}$ & 0.0059 \\
\hline$A C D C$ & $-11,377 \mathrm{C} \rightarrow \mathrm{G}$ & 0.0143 & AKAP10 & $\mathrm{A} \rightarrow \mathrm{G}(\mathrm{Ile} 646 \mathrm{Val})$ & 0.0070 \\
\hline$M M P 2$ & $-1306 \mathrm{C} \rightarrow \mathrm{T}$ & 0.0157 & $A P O E$ & $4070 \mathrm{C} \rightarrow \mathrm{T}(\operatorname{Arg} 158 \mathrm{Cys})$ & 0.0220 \\
\hline GP1BA & $1018 \mathrm{C} \rightarrow \mathrm{T}(\mathrm{Thr} 145 \mathrm{Met})$ & 0.0184 & CETP & $-629 \mathrm{C} \rightarrow \mathrm{A}$ & 0.0252 \\
\hline CAPN10 & $4852 \mathrm{G} \rightarrow \mathrm{A}(\mathrm{SNP}-43)$ & 0.0242 & APOA5 & $1131 \mathrm{~T} \rightarrow \mathrm{C}$ & 0.0288 \\
\hline UTS2 & $\mathrm{G} \rightarrow \mathrm{A}($ Ser89Asn $)$ & 0.0269 & $A G E R$ & $\mathrm{G} \rightarrow \mathrm{A}(\mathrm{Gly} 82 \mathrm{Ser})$ & 0.0308 \\
\hline PON1 & $584 \mathrm{G} \rightarrow \mathrm{A}(\mathrm{G} \ln 192 \mathrm{Arg})$ & 0.0339 & ESR1 & $-1989 \mathrm{~T} \rightarrow \mathrm{G}$ & 0.0349 \\
\hline PLAT & $-7351 \mathrm{C} \rightarrow \mathrm{T}$ & 0.0437 & $T N F$ & $-238 \mathrm{G} \rightarrow \mathrm{A}$ & 0.0372 \\
\hline$P C K 1$ & $-232 \mathrm{C} \rightarrow \mathrm{G}$ & 0.0477 & $L P L$ & $\mathrm{C} \rightarrow \mathrm{G}$ (Ser447Stop) & 0.0406 \\
\hline \multirow[t]{2}{*}{$F 7$} & $11,496 \mathrm{G} \rightarrow \mathrm{A}(\mathrm{Arg} 353 \mathrm{Gln})$ & 0.0488 & TNFSF4 & $\mathrm{A} \rightarrow \mathrm{G}$ & 0.0440 \\
\hline & & & $T N F$ & $-863 \mathrm{C} \rightarrow \mathrm{A}$ & 0.0443 \\
\hline
\end{tabular}

Supplementary Table II. Multivariable logistic regression analysis of polymorphisms associated with myocardial infarction in normotensive individuals.

\begin{tabular}{|c|c|c|c|c|c|c|c|c|c|}
\hline \multirow[t]{2}{*}{ Gene } & \multirow[t]{2}{*}{ Polymorphism } & \multicolumn{2}{|c|}{ Dominant model } & \multicolumn{2}{|c|}{ Recessive model } & \multicolumn{2}{|c|}{ Additive 1 model } & \multicolumn{2}{|c|}{ Additive 2 model } \\
\hline & & $\mathrm{P}$ & OR $(95 \% \mathrm{CI})$ & $\mathrm{P}$ & OR $(95 \% \mathrm{CI})$ & $\mathrm{P}$ & OR $(95 \% \mathrm{CI})$ & $\mathrm{P}$ & OR $(95 \% \mathrm{CI})$ \\
\hline$G P X 1$ & $\mathrm{C} \rightarrow \mathrm{T}$ (Pro198Leu) & 0.0364 & $0.60(0.37-0.96)$ & 0.7152 & & 0.0692 & & 0.7135 & \\
\hline$P T G S 2$ & $\mathrm{G} \rightarrow \mathrm{C}$ & 0.2047 & & 0.7279 & & 0.4130 & & 0.7273 & \\
\hline$T N F$ & $-850 \mathrm{C} \rightarrow \mathrm{T}$ & 0.3513 & & 0.0434 & $2.01(1.01-3.94)$ & 0.1003 & & 0.0737 & \\
\hline AKAP10 & $\mathrm{A} \rightarrow \mathrm{G}$ (Ile646Val) & 0.1983 & & 0.0142 & $2.12(1.15-3.83)$ & 0.0302 & $0.69(0.50-0.96)$ & 0.0389 & $1.90(1.02-3.46)$ \\
\hline$A P O E$ & 4070C $\rightarrow \mathrm{T}(\operatorname{Arg} 158 \mathrm{Cys})$ & 0.1018 & & 0.8742 & & 0.1045 & & 0.8727 & \\
\hline CETP & $-629 \mathrm{C} \rightarrow \mathrm{A}$ & 0.5340 & & 0.0312 & $1.40(1.03-1.90)$ & 0.1356 & & 0.4790 & \\
\hline APOA5 & $1131 \mathrm{~T} \rightarrow \mathrm{C}$ & 0.3465 & & 0.0644 & & 0.6921 & & 0.0624 & \\
\hline$A G E R$ & $\mathrm{G} \rightarrow \mathrm{A}(\mathrm{Gly} 82 \mathrm{Ser})$ & 0.6520 & & 0.0570 & & 0.3466 & & 0.0646 & \\
\hline ESR1 & $-1989 \mathrm{~T} \rightarrow \mathrm{G}$ & 0.7613 & & 0.1011 & & 0.8401 & & 0.1306 & \\
\hline$T N F$ & $-238 \mathrm{G} \rightarrow \mathrm{A}$ & 0.6481 & & 0.7787 & & 0.4568 & & 0.7790 & \\
\hline$L P L$ & $\mathrm{C} \rightarrow \mathrm{G}$ (Ser447Stop) & 0.1040 & & 0.4127 & & 0.0629 & & 0.4975 & \\
\hline TNFSF4 & $A \rightarrow G$ & 0.0196 & $1.49(1.06-2.07)$ & 0.1743 & & 0.0360 & $1.44(1.02-2.03)$ & 0.1349 & \\
\hline$T N F$ & $-863 C \rightarrow A$ & 0.0682 & & 0.2459 & & 0.1156 & & 0.1987 & \\
\hline
\end{tabular}

OR, odds ratio; CI, confidence interval. Multivariable logistic regression analysis was performed with adjustment for age, sex, body mass index, and the prevalence of smoking, hypercholesterolemia, and diabetes mellitus. 
Supplementary Table III. Polymorphisms related to myocardial infarction in individuals with or without hypercholesterolemia as determined by the chi-square test.

\begin{tabular}{|c|c|c|c|c|c|}
\hline \multicolumn{3}{|c|}{ Hypercholesterolemia (+) } & \multicolumn{3}{|c|}{ Hypercholesterolemia (-) } \\
\hline Gene & Polymorphism & $\mathrm{P}$ & Gene & Polymorphism & $\mathrm{P}$ \\
\hline$E N G$ & $\mathrm{C} \rightarrow \mathrm{G}$ (Asp366His) & 0.0082 & MTHFR & $677 \mathrm{C} \rightarrow \mathrm{T}(\mathrm{Ala} 222 \mathrm{Val})$ & 0.0002 \\
\hline$E D N R A$ & $-231 \mathrm{~A} \rightarrow \mathrm{G}$ & 0.0156 & $A G E R$ & $\mathrm{G} \rightarrow \mathrm{A}$ (Gly82Ser) & 0.0006 \\
\hline$A C E$ & $-240 \mathrm{~A} \rightarrow \mathrm{T}$ & 0.0168 & $A C D C$ & $-11,377 \mathrm{C} \rightarrow \mathrm{G}$ & 0.0033 \\
\hline$U C P 3$ & $-55 \mathrm{C} \rightarrow \mathrm{T}$ & 0.0193 & $A A C T$ & $\mathrm{G} \rightarrow \mathrm{A}($ Ala15Thr $)$ & 0.0037 \\
\hline АРОC 3 & $-482 \mathrm{C} \rightarrow \mathrm{T}$ & 0.0200 & $L P L$ & $\mathrm{C} \rightarrow \mathrm{G}$ (Ser447Stop) & 0.0042 \\
\hline F7 & $11,496 \mathrm{G} \rightarrow \mathrm{A}(\mathrm{Arg} 353 \mathrm{Gln})$ & 0.0303 & $F A B P 2$ & 2445G $\rightarrow$ A (Ala54Thr) & 0.0052 \\
\hline$I P F 1$ & $-108 / 3 \mathrm{G} \rightarrow 4 \mathrm{G}$ & 0.0425 & $I P F 1$ & $-108 / 3 \mathrm{G} \rightarrow 4 \mathrm{G}$ & 0.0053 \\
\hline TGFBR2 & $1167 \mathrm{C} \rightarrow \mathrm{T}($ Asn389Asn $)$ & 0.0462 & $F 7$ & 11,496G $\rightarrow \mathrm{A}(\mathrm{Arg} 353 \mathrm{Gln})$ & 0.0078 \\
\hline & & & AKAP10 & $\mathrm{A} \rightarrow \mathrm{G}(\mathrm{Ile} 646 \mathrm{Val})$ & 0.0194 \\
\hline & & & $A P O E$ & $4070 \mathrm{C} \rightarrow \mathrm{T}(\operatorname{Arg} 158 \mathrm{Cys})$ & 0.0213 \\
\hline & & & $T G F B 1$ & $-509 \mathrm{C} \rightarrow \mathrm{T}$ & 0.0269 \\
\hline & & & FLJ23476 & $\mathrm{C} \rightarrow \mathrm{A}($ Pro55Gln $)$ & 0.0273 \\
\hline & & & CETP & $-629 \mathrm{C} \rightarrow \mathrm{A}$ & 0.0308 \\
\hline & & & $F 12$ & $46 \mathrm{C} \rightarrow \mathrm{T}$ & 0.0331 \\
\hline & & & TNFSF4 & $A \rightarrow G$ & 0.0340 \\
\hline & & & PPARG & $-681 \mathrm{C} \rightarrow \mathrm{G}$ & 0.0435 \\
\hline & & & IRSI & 3494G $\rightarrow$ A (Gly972Arg) & 0.0480 \\
\hline
\end{tabular}

Supplementary Table IV. Multivariable logistic regression analysis of polymorphisms associated with myocardial infarction in individuals with hypercholesterolemia.

\begin{tabular}{|c|c|c|c|c|c|c|c|c|c|}
\hline \multirow[t]{2}{*}{ Gene } & \multirow[t]{2}{*}{ Polymorphism } & \multicolumn{2}{|c|}{ Dominant model } & \multicolumn{2}{|c|}{ Recessive model } & \multicolumn{2}{|c|}{ Additive 1 model } & \multicolumn{2}{|c|}{ Additive 2 model } \\
\hline & & $\mathrm{P}$ & OR $(95 \% \mathrm{CI})$ & $P$ & OR $(95 \% \mathrm{CI})$ & $\mathrm{P}$ & OR $(95 \% \mathrm{CI})$ & $\mathrm{P}$ & OR $(95 \% \mathrm{CI})$ \\
\hline$E N G$ & $\mathrm{C} \rightarrow \mathrm{G}$ (Asp366His) & 0.1533 & & 0.0288 & $0.68(0.48-0.96)$ & 0.0340 & $3.46(1.13-11.5)$ & 0.1895 & \\
\hline EDNRA & $-231 \mathrm{~A} \rightarrow \mathrm{G}$ & 0.0285 & $0.72(0.53-0.96)$ & 0.0940 & & 0.0835 & & 0.0166 & $0.66(0.47-0.93)$ \\
\hline$A C E$ & $-240 \mathrm{~A} \rightarrow \mathrm{T}$ & 0.1941 & & 0.0547 & & 0.4791 & & 0.0408 & $0.68(0.47-0.98)$ \\
\hline$U C P 3$ & $-55 \mathrm{C} \rightarrow \mathrm{T}$ & 0.0065 & $1.39(1.10-1.77)$ & 0.3447 & & 0.0107 & $1.39(1.08-1.79)$ & 0.1060 & \\
\hline APOC 3 & $-482 \mathrm{C} \rightarrow \mathrm{T}$ & 0.1082 & & 0.2062 & & 0.2038 & & 0.0788 & \\
\hline$F 7$ & $11,496 \mathrm{G} \rightarrow \mathrm{A}(\mathrm{Arg} 353 \mathrm{Gln})$ & 0.3270 & & 0.0704 & & 0.5853 & & 0.0689 & \\
\hline IPFI & $-108 / 3 \mathrm{G} \rightarrow 4 \mathrm{G}$ & 0.0554 & & 0.9525 & & 0.0444 & $0.73(0.54-0.99)$ & 0.1942 & \\
\hline$T G F B R 2$ & $1167 \mathrm{C} \rightarrow \mathrm{T}($ Asn389Asn $)$ & 0.0617 & & 0.0596 & & 0.1701 & & 0.0336 & $0.58(0.35-0.95)$ \\
\hline
\end{tabular}

OR, odds ratio; CI, confidence interval. Multivariable logistic regression analysis was performed with adjustment for age, sex, body mass index, and the prevalence of smoking, hypertension, and diabetes mellitus.

Supplementary Table V. Polymorphisms related to myocardial infarction in individuals with or without diabetes mellitus as determined by the chi-square test.

\begin{tabular}{|c|c|c|c|c|c|}
\hline \multicolumn{3}{|c|}{ Diabetes mellitus (+) } & \multicolumn{3}{|c|}{ Diabetes mellitus (-) } \\
\hline Gene & Polymorphism & $\mathrm{P}$ & Gene & Polymorphism & $\mathrm{P}$ \\
\hline$A P O E$ & 4070C $\rightarrow \mathrm{T}$ (Arg158Cys) & 0.0040 & CETP & $-629 \mathrm{C} \rightarrow \mathrm{A}$ & 0.0031 \\
\hline AKAP10 & $\mathrm{A} \rightarrow \mathrm{G}(\mathrm{Ile} 646 \mathrm{Val})$ & 0.0090 & $L P L$ & $\mathrm{C} \rightarrow \mathrm{G}$ (Ser447Stop) & 0.0059 \\
\hline RECQL2 & $\mathrm{T} \rightarrow \mathrm{C}$ (Cys1367Arg) & 0.0155 & COMT & $\mathrm{G} \rightarrow \mathrm{A}($ Val158Met $)$ & 0.0126 \\
\hline$A P O E$ & $3932 \mathrm{~T} \rightarrow \mathrm{C}(\mathrm{Cys} 112 \mathrm{Arg})$ & 0.0236 & MTHFR & $677 \mathrm{C} \rightarrow \mathrm{T}(\mathrm{Ala} 222 \mathrm{Val})$ & 0.0127 \\
\hline$F A B P 2$ & 2445G $\rightarrow$ A (Ala54Thr) & 0.0295 & $T N F$ & $-863 \mathrm{C} \rightarrow \mathrm{A}$ & 0.0141 \\
\hline MTHFR & $677 \mathrm{C} \rightarrow \mathrm{T}(\mathrm{Ala} 222 \mathrm{Val})$ & 0.0310 & $G P 1 B A$ & $1018 \mathrm{C} \rightarrow \mathrm{T}$ & 0.0141 \\
\hline PAII & $\mathrm{A} \rightarrow \mathrm{G}(\mathrm{Tyr} 243 \mathrm{Cys})$ & 0.0317 & PON1 & $584 \mathrm{G} \rightarrow \mathrm{A}(\mathrm{Gln} 192 \mathrm{Arg})$ & 0.0179 \\
\hline PON1 & $\mathrm{A} \rightarrow \mathrm{G}$ (Arg160Gly) & 0.0337 & $F A B P 2$ & 2445G $\rightarrow$ A (Ala54Thr) & 0.0181 \\
\hline$I P F 1$ & $-108 / 3 \mathrm{G} \rightarrow 4 \mathrm{G}$ & 0.0366 & $I P F 1$ & $-108 / 3 \mathrm{G} \rightarrow 4 \mathrm{G}$ & 0.0194 \\
\hline \multirow[t]{2}{*}{$A G E R$} & $\mathrm{G} \rightarrow \mathrm{A}($ Gly82Ser $)$ & 0.0392 & PTGS2 & $\mathrm{G} \rightarrow \mathrm{C}$ & 0.0201 \\
\hline & & & $F 7$ & $11,496 \mathrm{G} \rightarrow \mathrm{A}(\mathrm{Arg} 353 \mathrm{Gln})$ & 0.0237 \\
\hline
\end{tabular}

